\title{
Evaluation of Garment Flammability using Thermal Mannequins
}

\author{
Y. UEHARA and M. UMEZAWA \\ Department of Safety Engineering \\ Division of Materials Science and Chemical Engineering \\ Faculty of Engineering \\ Yokohama National University \\ 156 Tokiwadai, Hodogaya-ku, Yokohama 240, Japan
}

ABSTRACT

The flammability of garments was studied using thermal mannequins with sensors which were dressed in 73 sets of clothes comonly available in Japan. The results showed that all of them, except for 18 sets, were highly flammable and indicated a possibility of serious fire injuries with in a short time. The maximum temperature and the maximum heat flux obtained on the body surface were $437^{\circ} \mathrm{C}$ and $335 \mathrm{~kJ} / \mathrm{m} 2 \mathrm{~s}$, respectively. To evaluate the hazards, method of evaluation based on the burning rate, size and degree of fire injury plus a combination of these factors were proposed to be useful.

\section{INTRODUCTION}

Clothing, together with food and housing, is the most basic factor in our daily life and indispensable in maintaining protection of the body against cold weather and outer hazards. However, some garments are so flammable that a large number of casualties are the result of garment fires every year. Being aware of the hazards, several countries in the wor ld have already established standards of flame proof garment which are centered on children's nightclothes, or restrictions have been placed on garments.

This paper intends to explain garment fires in $J$ apan and to report on the classification of garment flammability based on tests using thermal mannequins dressed in everyday clothes.

\section{GARMENT FIRES IN JAPAN}

Of the 1,332 total deaths, except for suicidal arson, 130(9.8\%) were caused by garment fires in 1978, according to the "process to Death" in the white Paper on Fire service (1). The death toll by garment fires accounts for 180(13.8\%) of 1,301 deaths in 1979 and $141(11.48)$ of 1,238 in 1980 (143(13.0\%) of 1,096 in 1982 and $153(13.3 \%)$ of 1,152 in 1983). Of the 491 total deaths, except for suicidal arson, 50 are considered to have been caused by garment fires within the jurisdiction of the Tokyo Fire Department Agency during the five years from 1975 through 1979. This rate is a lmost equal to that in the white paper on Fire Service (2). The rates consist of only the cases where clothes caught fire directly from a flame. If those cases of fires transferred by intermediaries are included, such as where a cigarette smoked in bed ignited bedding which then transferred to night clothes, or where leaked oil caught fire and spread to garments when an oil stove was accidentally overturned, the 
death toll by garment fires amounts to 128 out of 491 deaths.

of those total deaths, people over 61 and children under 10 account for 50.6\% and $12.6 \%$, respectively. Gir is under 5 account for a remarkably high percentage among children.

\section{EXPERIMENTS}

\section{Experimental Apparatus (Thermal Mannequins)}

The manequins emp loyed in this study were those on the market and manufactured by FRP. Their surface was covered with an asbestos and cement mixture with a thickness of 5 to $10 \mathrm{~mm}$ to provide them with heat resistance. Heat conductivity of asbestos-cement is $1.67 \mathrm{~kJ} / \mathrm{m} \mathrm{h}$ deg at $90^{\circ} \mathrm{C}$, and is close to 1.80 to $2.72 \mathrm{~kJ} / \mathrm{m} \mathrm{h}$ deg, which is the heat conductivity of human skin obtained at 23 to $25^{\circ} \mathrm{C}$. Three types of thermal mannequins were designed: one with a height of $175 \mathrm{~cm}$ for a male, one with a height of $166 \mathrm{~cm}$ for a female and another with a height of $113 \mathrm{~cm}$ for a child. To measure heat $f 1 \mathrm{ux}$, a $0.3 \mathrm{~mm}$ chromel-alumel thermocouple was welded onto the center of $15 \mathrm{~mm}$ diameter and 1 mm thick copper-plates. The surface of these sensors was coated with black heat resistant paint to increase heat absorption. Eight such thermoplates were installed on the mannequin and their positions are shown in Fig.l. These thermoplates were calibrated using a black body radiation surface. Conducting wires of the thermoplates were taken out from the wrists and heels of the mannequins.
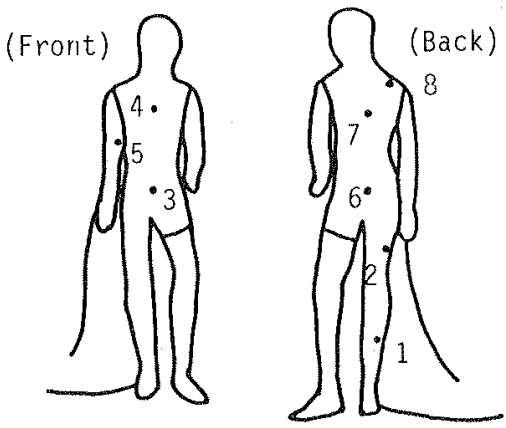

Fig. 1 A Thermal Mannequin (Male) and Position of Sensors

Samples

Generally, in burning tests the results are not always consistent even though the same samples are employed. Thus, tests are usually performed several times under the same conditions. However, since there are many types of garments, it is not possible to test all of them. This explain why relatively simple styled garments, such as nightclothes and A-line, one piece dresses, had mostly been used in past thermal mannequin tests $(3-6,15)$. In the present tests, samples which cover as many types of garments as possible, ranging from nightclothes to suits including underwear, were selected and examined under the same conditions used every day. Detailed descriptions of the samples are omitted here due to the limitation of papers. However, care was taken to ensure that main fabrics, such as cotton, polyester, nylon, silk, wool and 
acrylic fiber, were covered. The samples were brand-new and no special pretreatment was carried out.

\section{Test Method and Items}

The tests were carried out in a laboratory room with a floor space of $55 \mathrm{~m}^{2}$ and $7.85 \mathrm{~m}$ high. Air flow was generated by ventilating fans at a velocity of 0.2 to $0.3 \mathrm{~m} / \mathrm{s}$ at a position $1 \mathrm{~m}$ above the floor from the left front to the right of a mannequin during the tests. Ignition was made on contact with a diffused flame for 10 seconds using a Bunsen burner charged town gas $(46,000 \mathrm{~kJ} / \mathrm{m} 3)$ at a velocity of $325 \mathrm{ml} / \mathrm{min}$. Ignition place were in principle: in trousers, the front bottom of the leg on which a sensor was installed; in skirts and kimonos, the front hem. The burnings were recorded by VTR and photographed. outputs of the thermoplates were also continuously recorded during the tests. The following were obtained from the temperature curve based on the output of the thermoplates:(1) the time required from contact with a flame to the beginning of combustion; (2) the time required from the beginning of combustion to the peak; (3). the peak temperature; (4) the maximum heat flux; (5) the time required from contact with a flame to causing a second degree burn.

Here, a second degree burn means a burn which injured depth is 100 micrometers or which has blisters and some broken skin. Henrique, sto11, Greene, Chienta and others have the relation between a second degree burn and heat flux (7-11). The time required for a second degree burn was determined by measuring heat flux at various times. The maximum heat flux was obtained from the output of the thermoplates that provided the sharpest slope during the time from the beginning of combustion to its peak.

\section{RESULTS}

\section{Comparison of Flammability}

Tests were conducted on 73 sets of general everyday garments, of which men's, 1adies', boys' and girls' were numbered 18,27, 14 and 14, respectively. Of all the samples, 18 sets of garments were not ignited by a 10-second contact with a flame of a bunsen burner or the fire self-extinguished after a small part was burnt. The remaining 55 sets were readily ignited and blaze up.

\section{Flammability of Various Garments}

Yukata dresses (cotton kimonos for summer wear). Nightclothes generally showed high flammability and yukata dresses in particular were highly combustible. In a test using a female mannequin dressed in a pure cotton yukata and ny 1 on underwear, flames reached near the face in 8 seconds after ignition, then flared up to $50 \mathrm{~cm}$ over the head. The yukata itself was al most totally consumed in a minute and 10 seconds. At the back waist, the maximum temperature and the maximum heat flux were $300^{\circ} \mathrm{C}$ and $138 \mathrm{~kJ} / \mathrm{m} 2 \mathrm{~s}$, respectively; it took 21 seconds to produce a second degree burn. At the jaw, the maximum temperature was $108^{\circ} \mathrm{C}$ and the maximum heat $f 1 \mathrm{ux} 25.1 \mathrm{~kJ} / \mathrm{m} 2 \mathrm{~s}$. The time required for a second degree burn was 43 seconds.

Pajamas. A test of male mannequin wearing a cotton, short-sleeved pajama jacket and trousers, a cotton short-sleeved undershirt with a $U$ shaped neck, and cotton briefs with a $15 \%$ polyester blend, demonstrated that filames exten- 
ded to the face 20 seconds after ignition on contact with a gas flame. The garment a lmost burnt up in one minute and $40 \mathrm{seconds.} \mathrm{Figure} 2$ shows the relationship between the time and the temperature and heat flux at measuring points. The maximum temperature of $149^{\circ} \mathrm{C}$ and the maximum heat flux of $110 \mathrm{~kJ} / \mathrm{m} 2 \mathrm{~s}$ were obtained at the waist and hips, respectively. In the latter, it took 18 seconds to produce a second degree burn.
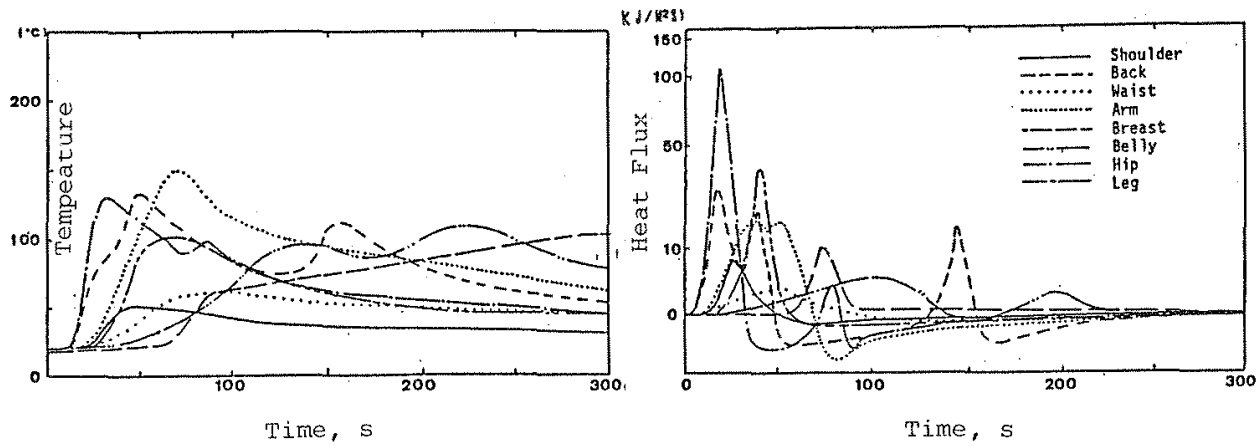

Fig. 2 Time Dependence of Temperature and Heat Flux (Ml)

Negligees. A test was conducted using a female mannequin with a cotton short-sleeved negligee, a nylon of a polyurethane mix and cotton panties. Flames reached the face 12 seconds after contact with a gas flame and the garment was consumed within one minute and 30 seconds. The maximum heat flux at the waist and that at the left arm were $139.7 \mathrm{~kJ} / \mathrm{m} 2 \mathrm{~s}$ and $58.6 \mathrm{~kJ} / \mathrm{m} 2 \mathrm{~s}$, respectively.

Suits. In a test of wolen suits, a small flame was raised by a $10-$ second contact with a gas flame on the bottom of the $r$ ight leg. However, it extinguished immediately when the gas flame was removed. Then a $25-$ second contact with a flame was made on the back bottom of the jacket. The lininig (55\% cuprammonium rayon and $45 \%$ nylon) caught fire and spread to the shirt and the combustion reached its peak one minute and 20 seconds later. Eight minutes were required until the suits were completely consumed. A similar situation occurred with polyester suits with $45 \%$ wool. They were ignited when touched with a flame on the front bottom of the jacket for 15 seconds. A fire extended to the face in one minute and 20 seconds afterward, and the combustion reached its peak 5 minutes and $30 \mathrm{~seconds}$ later. It took 16 minutes until most of the suites were consumed.

These two types of suits were relatively flame proof. They began burning only when the lining was ignited. However, cotton corduroy suits exhibited a rapid combustion owing to the fluffy surface. Flames reached the face in one minute and 30 seconds and it took 2 minutes until the burning reached its peak. The maximum temperature and the maximum heat $\mathrm{flux}$ were $208 \mathrm{C}$ and $46.0 \mathrm{~kJ} / \mathrm{m} 2 \mathrm{~s}$, respectively, at the foot. It took 27 seconds to produce a second degree burn.

Jeans. Cotton jeans were ignited after being touched with a flame for 10 seconds. Since they fit the body tight ly, their burning rate is low; it took 5 minutes before the flame reached the femur. In two types of jeans, the fire self-extinguished at the femur. Although modes of combustion were similar, big flames occurred in the other type and a fire transferred to a polo shirt 
in one minute and 30 seconds, or an acrylic sweater in 2 minutes.

Combination of sweaters and skirts or trousers (including pantaloons). It is difficult to generalize the flammability of these combinations because their modes of combustion are greatly affected by combination. For example, the bottom portion may be dressed in flammable. skirt or trousers, and if the upper portion may be dressed in a sweater with high wool content it will not catch fire easily. On the contrary, the more acrylic fiber contained in the garment, the more flammable it becomes. An example is given by a female mannequin wearing an acrylic sweater and an acrylic skirt with 250 polyester and $5 \%$ wool. In this test, flames reached the jaw 30 seconds after ignition, where the maximum temperature of $344^{\circ} \mathrm{C}$ and the maximum heat flux of $334.7 \mathrm{~kJ} / \mathrm{m} 2$ $s$ were obtained. It is considered that these high values were obtained because flames attacked the sensor directly.

Combination of shirts (blouses) and skirts or trousers. In a test of a female mannequin with a T-shirt and a skirt, the latter exhibited fierce combustion. The face was covered in flames 30 seconds later and the skirt was burnt out in one minute and 30 seconds to 3 minutes. On the contrary, the Tshirt was not severely damaged. In a combination of a blouse and a polyester skirt, the latter was not ignited but melted in drops. However, fierce combustion was observed in the case where underwear caught fire which spread to the blouse.

Tests of boys' T-shirts and short pants presented low burning rates with small damage to the T-shirts, regardless of the pants being cotton or polyester.A comparison between a combination of a $\mathrm{T}$-shirt with a skirt and that of a $\mathrm{T}-$ shirt with short pants proved that the former was greatly hazardous.

One-piece dresses. Most of the one-piece dresses were readily ignited. Flames covered the face 20 to 30 seconds after a gas flame touched the dress and the garment burnt up about 2 minutes and 30 seconds later. An example is given by a test of a sleeveless, polyester, one-piece dress with a 35\% cotton mix. The maximum temperature and the maximum heat flux at the abdomen were $172^{\circ} \mathrm{C}$ and $68.5 \mathrm{~kJ} / \mathrm{m} 2 \mathrm{~s}$, respectively.

Kimono dresses. A woolen men's kimono ensemble (a kimono dress and a short coat) with $15 \%$ silk and 5\% nylon blended, was ignited after a 10-seconds contact with a gas flame. However, the fire extinguished 40 seconds later. Contact with a gas flame was again made on the bottom of the right sleeve for 20 seconds. The polyester lininig caught fire and flames leapt up to the face one minute and 30 seconds later. Two minutes and 30 seconds were required until the combustion reached its peak and 9 minutes were required until most of the clothes burnt out. A maximum temperature of $212^{\circ} \mathrm{C}$ and a maximum heat flux of $20.1 \mathrm{~kJ} / \mathrm{m} 2 \mathrm{~s}$ were obtained at the waist and the back, respectively.

A silk ladies' kimono was not ignited, although a flame was in contact for 10 seconds. The fire extinguished burning a small part of the lining only. Then, contact with a flame was made on the bottom of the sleeve for 20 seconds; however, the kimono did not ignite and only the ignition place was carbonized. Lastly, an obi (a sash belt, the outer side of which is polyester and the lininig rayon) was ignited after a 10-second contact with a flame and exhibited an extremely duli combustion. A maximum temperature of $437^{\circ} \mathrm{C}$ was measured at the arm approximately 5 minutes 50 seconds later. The maximum heat $\mathrm{flux}$ of $25.1 \mathrm{~kJ} / \mathrm{m} 2 \mathrm{~s}$ was observed at the abdomen.

Working clothes. A polyester working garment with a $20 \%$ cotton blend was ignited after being touched with a flame for 10. seconds. Al though the combus- 
tion was slow, flames spread over the clothes. The maximum temperature was obtained at the back 7 minutes 1 ater and the maximum heat flux indicated $3.3 \mathrm{~kJ} / \mathrm{m} 2 \mathrm{~s}$. Another one, made of aromatic polyamide, did not exhibit a flame at all and only the part which was directly touched with a gas flame was carbonized although it was exposed to a gas $f 1$ ame for a long period.

Sports wear. Polyester sports wear was tested and when ignited, they melted fiercely, falling down in arops. The part which were burnt peeled off. Therefore, they exhibited a low apparent flame propagating rate and the temperature of the body did not increase. Therefore, good results were obtained from the tests. However, in one of them, a sudden rise in temperature was observed at the abdomen 3 minutes later and it exceeded $250^{\circ} \mathrm{C} 4$ minutes and 30 seconds later.

Coats. Three types of coats, a polyester one blended with $40 \%$ w001, a polyester one with $35 \%$ cotton and a $100 \%$ cotton one, were tested. In a 11 tests, flames spread to the face one minute to one minute and 20 seconds after coming into contact with a gas flame. The combustion reached its peak one minute and 30 second later. However, in the case of coats, clothes put on under a coat, such as suits, greatly affected the combustion; the heat $f l u x$ on the body surface became small because of the suits. Thus, a higher safety mark was given to the coats than one would assume from the appearance of combustion.

Comparison with past tests

In the present tests, the heat flux of 4 to $84 \mathrm{~kJ} / \mathrm{m} 2 \mathrm{~s}$ is frequently obtained. A heat $f l u x$ of $335 \mathrm{~kJ} / \mathrm{m} 2 \mathrm{~s}$, the maximum of all measured, is obtained once. on the other hand, the maximum temperature generally does not exceed $300 \mathrm{C}$, although the temperature of $437^{\circ} \mathrm{C}$ is observed once.

Finley and others (3-5) recorded the maximum heat $\mathrm{Elux}$ of $11 \mathrm{~kJ} / \mathrm{m} 2 \mathrm{~s}$ and the maximum temperature of $204^{\circ} \mathrm{C}$ in a test of a cotton A-shaped one-piece dress, in which the time taken to reach the peak of combustion was 37 seconds.

In the tests of flammability of yukata dresses designed by the Ministry of International Trade and Industry of Japan, the maximum heat flux was 4.2 to $13.4 \mathrm{~kJ} / \mathrm{m} 2 \mathrm{~s}$ and it took about 35 to 55 seconds to obtain the highest value (12).

The temperature and time given by these two tests nearly coincide with those of the present tests. However, the heat flux seems to be a little lower in their tests.

On the contrary, in ohya's experiments (13), the heat flux of $250 \mathrm{~kJ} / \mathrm{m} 2 \mathrm{~s}$ was frequent ly observed, and that of $355 \mathrm{~kJ} / \mathrm{m} 2 \mathrm{~s}$ was also reported. The time to the peak of combustion is 30 to 50 seconds which is a little longer than the value measured in the present tests. Hence, it can be said that the values shown in the present tests were proved to be appropriate.

Summary of Garment Flammability Tests

Elammable garments. The results of fire tests are sumarized as follows:

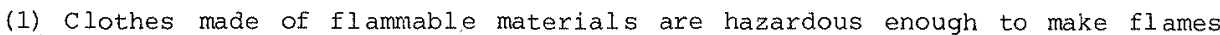
reach the face in 10 to 90 seconds. Heat flux was generally 4 to $84 \mathrm{~kJ} / \mathrm{m} 2 \mathrm{~s}$ but $335 \mathrm{~kJ} / \mathrm{m} 2 \mathrm{~s}$ was observed as the maximum flux once.

(2) It is difficult to make a conclusion owing to various factors; however, 
cotton, acrylic clothes, those of a mixture of cotton and polyester and those of a mixture of cotton and acryl are relatively flamable. Silk, woolen, nylon and aromatic polyamide clothes are relatively flame proof.

(3) In cotton clothes, thick textures, such as jeans, exhibit a very low burning rate. On the contrary, a mixture of cotton and polyester and that of cotton and acryl are relatively flammable regardless of their thickness.

(4) In clothes which are made of cotton and polyester and fit the body relatively we11, the fibers contract and the clothes shrink to the surface of a mannequin when heated. A fire self-extinguished because of the shortage of air in most cases. It is difficult to classify this type of case because it appears to be flame proof. On the other hand, the heat contraction of fibers is small in clothes of a mixture of cotton and acryl, therefore, fire spreads. (5) Generally, girls' wear is flammable in both materials and forms. More attention should be paid to this.

Nonflammable garments. As was mentioned above, 18 sets of all the garments were not ign ited by the first contact with a gas flame for 10 seconds. The reasons of self-extinguishment of almost the garments are due to melt, drip or shrink of tex-tiles, or the fitness of clothes. After all, only the garments made of wool, silk, mixture of wool and nylon and aromatic polyamide were found to be substantially flame proof.

PROPOSAL OF A NEW TEST METHOD FOR THE CLASSIFICATION OF GARMENT FLAMMABILITYY USING TRERMAL MANNEQUINS

\section{Classification Method}

To classify garment flammability using thermal mannequins, three measurements, such as burning rate, size of degree of fire injuries were introduced.

Burning rate. After fire tests were performed, the mean times required to cause a second degree burn at various parts were calculated. These values were classified into four classifications as shown in the following. The percentages are also 1 isted for each group for the 73 sets of garments.

Classification

A
$B$
C
D

Size of fire injuries. Classification was made by the total number of second degree burns as follows:

Classification

Type

Rate $(\%)$

A
B
C
D

1 - 2 places

12

3 - 4 places

5 - 6 places

7 - 8 places

18

44

26

Degree of fire injuries. The mean maximum heat flux was calculated for 
portions where the maximum heat flux was larger than $2.9 \mathrm{~kJ} / \mathrm{m} 2 \mathrm{~s}$, designed as the degree of fire injury and classified as follows:

Classification Type Rate (\%)

$\begin{array}{lll}\text { A } & 10 \mathrm{~kJ} / \mathrm{m} 2 \mathrm{~s} \text { or less } & 12 \\ \mathrm{~B} & 10-20 \mathrm{~kJ} / \mathrm{m} 2 \mathrm{~s} & 44 \\ \mathrm{C} & 21-30 \mathrm{~kJ} / \mathrm{m} 2 \mathrm{~s} & 22 \\ \mathrm{D} & 30 \mathrm{~kJ} / \mathrm{m} 2 \mathrm{~s} \text { or more } & 22\end{array}$

General classification. Using the above three evaluation standards, me asurements, $A, B, C$ and $D$ were given $4,3,2$ and 1 point, respectively, and the general classification of garment flamability was evaluated by counting the points. The results are follows:

Classification

A
B
C
D

Type

$$
\begin{array}{r}
11-12 \text { points } \\
8-10 \text { points } \\
5-7 \text { points } \\
3-4 \text { points }
\end{array}
$$

Rate $(\%)$

$$
\begin{aligned}
& 11 \\
& 34 \\
& 41 \\
& 14
\end{aligned}
$$

\section{Discussion on the General Classification}

Classification results are shown in Table 1. Judging from the general classification, working cloth made of fire resistant fiber provided good results without doubt. Classified into class $A$ are a combination of a woolen sweater and trousers, that of a woolen jumper and trousers with a nylon blend, polyester sports wear, woolen suits, suits of wool and nylon, a combination of a cotton T-shirt and trousers blended with polyester. These clothes are flame proof in material and fit the body relatively well. Good results were obtained in polyester sports wear because they melted fiercely and fell in drops when ignited. However, they should be re-examined.

Clothes which come under class $B$ in the general classification are a combination of a $\mathrm{T}-\mathrm{sh} i \mathrm{xt}$ and trousers, that of a $\mathrm{T}$-shirt and jeans, kimono aresses and a combination of a shirt and trousers, arranged according to superiority in other classifications. They are relatively difficult to burn except for kimono dresses. Therefore, good results were yielded although many of them were cotton. Kimono dresses made of wool or silk were difficult to burn. Listed in a lower rank of class $B$ are two-piece dresses, a combination of a polo shirt and pantaloons, that of a sweater and a skirt and cotton suits. Their materials are flammable and many of them are ladies' wear.

Coupled within a high rank of class $C$ are a combination of a shirt and trousers, pajamas and one-piece dresses. Those listed in a lower rank are a combination of a $\mathrm{T}$-shirt and a skirt, one-piece dresses, negligees and so on. Most of them are ladies' wear and some girls' wear is included.

Those classified into class $D$, the lowest group, are all kinds of nightolothes such as yukata dresses and pajamas, sports wear and a combination of a T-shirt and skirt. This classification evidently shows how flammable nightclothes are. 
The results of the general classification obtained after those three evaluation standards are completely identical with experimental results. Besides, points are given according to the level of safety, and it is clear that the proposed method allows a useful and quantitative evaluations of the safety of garments from fire.

Table 1 Classification of Garmenis According to the Proposed Method

\begin{tabular}{|c|c|c|c|c|c|c|c|}
\hline${ }_{-1}^{\text {No }}$ & daringt & $\begin{array}{r}\text { Composition } \\
+2\end{array}$ & 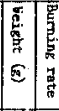 & 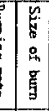 & 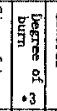 & & 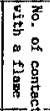 \\
\hline \begin{tabular}{|ll}
$B$ & 1 \\
\end{tabular} & 1 I- shlirt \& trousers & C170,PE30/Cr100 & 149 & $B 4$ & $A B A$ & & \\
\hline $\begin{array}{ll}B 2 \\
\end{array}$ & 2 -shirt \& trousers & C1100/CI85,PU5 & 173 & $A 2$ & & & \\
\hline B & $8 y-\operatorname{shdrt} \&$ trousers & PE65,CI35/PE5OCI5O & 2298 & C1 & & & \\
\hline $\begin{array}{ll}B & 4 \\
\end{array}$ & to shirt o trousers & ETIO0/PREO, Ct20 & 210 & c5 & 5 & & \\
\hline $\begin{array}{ll}B & 5 \\
\end{array}$ & 8 -shlirt 8 trousers & PE65, C1 & $154 \Lambda$ & B 4 & & & \\
\hline $\begin{array}{lll}\mathrm{B} & 6 \\
\end{array}$ & Tukata dress & critoo & $109 \mathrm{C}$ & $\mathrm{DB}$ & 8 & & \\
\hline $\begin{array}{ll}8 & 7 \\
\end{array}$ & Yukata dress & En100 & 2980 & D 7 & & & \\
\hline $\begin{array}{ll}B & 8 \\
\end{array}$ & 3 Gosana (ho If s leeve) & 01100 & 14: B & D ? & a s a & & \\
\hline$B$ & Pojoma (half sloeve) & crioo & $1 4 \longdiv { B }$ & $D 8$ & & & \\
\hline$B 10$ & Pukata dress & $\pi 100$ & $20 \sqrt{0}$ & 07 & 50 & & \\
\hline $\overrightarrow{B 11}$ & Pasema (half sleeve) & Criog & $167 \mathrm{~B}$ & 58 & 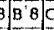 & & \\
\hline 812 & Pratining vear & E100 & $4 6 \longdiv { B }$ & $\Lambda 1$ & Bi & & 2 \\
\hline$B 13$ & Svester \& Jeans & $\operatorname{mingo,n}$ & $23: A$ & C 6 & 87 & & \\
\hline 814 & Sueater 8 trousers & $4000 / 0$ & 16 . & $\Delta 1$ & $A 2$ & & \\
\hline $\begin{array}{ll}a & 1 \\
\end{array}$ & f 1 -shirt 8 skirt & crioo/p & 1390 & B 4 & 87 & & \\
\hline$G$ & Tmshlrt $18 \mathrm{kirt}$ & $\operatorname{ct100}$ & $22 \sqrt{\mathrm{C}}$ & D8 & co & & \\
\hline$G$ & T-shlrt 8 skirt & $\cos 50$. & 1330 & C6 & 560 & & \\
\hline $\mid \begin{array}{llll}a \\
M\end{array}$ & T-ghirt \& skitt & {$[\mathrm{CT} 50, \mathrm{PE} 50 / \mathrm{Cr} 100$} & $144 \mathrm{C}$ & D7 & D? & & \\
\hline$a$ & Wukata dress & crioo & 28 茄 & $\mathrm{C}^{6}$ & 070 & & \\
\hline 6 & Pugang (half sleeve) & crioo & $137 \mathrm{D}$ & D 8 & $\mathrm{DB}$ & & \\
\hline 7 & Fasses (half sleeve) & $\mathrm{E} 7 \mathrm{75}, \mathrm{P}$ & $170 \mathrm{c}$ & D 8 & $\mathrm{CB}$ & & \\
\hline 8 & greplece dress & $\mathrm{CIa0, \textrm {PE } 2}$ & $130 \mathrm{C}$ & C 5 & $B 6$ & & \\
\hline g) & Dne-plece dress & $c 1100$ & $148 \mathrm{C}$ & CE & $B 6$ & & \\
\hline 010 & Sa daug (ha1f sloeve) & CI50,PE50 & $7 \pi \mathrm{C}$ & $A 1$ & $0 \pm 0$ & & \\
\hline a11 & me-plece dress & PE100 & $15 \% \mathrm{C}$ & CE & B 5 & & Drip \\
\hline 612 & soeater skirt & EGSRY39 & $16: \mathrm{C}$ & Ba & $C 2$ & & \\
\hline G 13 & syeater skirt & 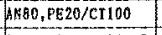 & $175 \mathrm{~B}$ & C6 & $B 7$ & & \\
\hline C14 & seeater skirt & AMLOO/ & 1000 & C6 & 106 & & \\
\hline i. & One-plece & PE10 & 1894 & c5 & 56 & & Drif \\
\hline 2 & Neg11800 & crivo & $14 \mathrm{DD}$ & cs & $D 7 D$ & & \\
\hline $\mathrm{L}$ & Pajasa & 61100 & $17 \mathrm{dC}$ & D7 & Cac & & \\
\hline & Jegligen, haIL ale & deiso, & $17] \mathrm{C}$ & $\mathrm{c} 6$ & a 76 & & \\
\hline 5) & Blouse e sklrt & FEG5,CT35/PE100 & $216 \Lambda$ & $c 6$ & $\mid c 6$ & & $20 r$ \\
\hline
\end{tabular}

\begin{tabular}{|c|c|c|c|c|c|}
\hline L $\quad 6$ & 6 ene-plece dress & crioo & $253 \mathrm{D}$ & C E $\mathrm{BE}$ & \\
\hline 4.7 & 7 Dne place dress & PE65,Cr35 & $27 \mathrm{C}$ & & \\
\hline $\begin{array}{ll}\mathrm{L} & \mathrm{B} \\
\end{array}$ & B 1louge / skirt & E100/PR100 & $377 \mathrm{~B}$ & B $303 / B$ & 3 Dr. \\
\hline$L$ & OPolo \& Pantaloon & ETSO,PEDO/CTSOPBSO & $492 \Lambda$ & CE B B & \\
\hline $\begin{array}{llll}1 & 1 & 0 \\
\end{array}$ & oblouse $\mathrm{skk1rt}$ & CI80, AY20/PE100 & 410 & C6 B6 & \\
\hline L. 11 & 1 Pagasuf (balf sleeve) & CT70, PESO & $217 \mathrm{~B}$ & C 6 C 6 & 2 \\
\hline L 12 & 2 Cardigan a pantaloon & Nit $100 / \mathrm{CI} 50, \mathrm{PE} 60$ & $256 \mathrm{~B}$ & 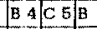 & \\
\hline 413 & 3 polo \& Pa & $\mathrm{E} 52, \mathrm{CT} 48$ & $529 \mathrm{~B}$ & C 6 B 7 B & \\
\hline L 14 & $4 \mathrm{~T}_{\text {-shlet }}$ Jeans & CT50, PESO & 539 A & $A \perp D 1 B$ & 2 \\
\hline L 15 & 5 Yukets dress & CT100 & $325 \mathrm{C}$ & C5 57 & \\
\hline$L 16$ & 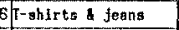 & $67100 / 61100$ & $577 \mathrm{~A}$ & \begin{tabular}{|l|l|l|} 
B 34 & B \\
\end{tabular} & \\
\hline$L 17$ & 7 Yukate dress & EE65,Ct35 & $499 \mathrm{C}$ & $D \geqslant C 7 c$ & \\
\hline $\begin{array}{llll}L & 1 & 8\end{array}$ & Bpolo \& Jeans & PEG5,Cras/c & 600 & C 5 C $6 \mathrm{~B}$ & 2 \\
\hline L. 18 & g vesligen, half & SiL.100 & 1780 & $\begin{array}{lll}A 1 & D 2 & C \\
\end{array}$ & 2 \\
\hline L 20 & Truining pear & PEI00 & 681 & A 2 B S A & 2 \\
\hline L 21 & i pa jang (half sleavo) & C170, PE30 & $217 \mathrm{~B}$ & $\begin{array}{lll}\text { C } 5 \text { C } & \text { C } \\
\end{array}$ & \\
\hline$\overline{L 22}$ & Pme-plece dress & AN94, & $712 \mathrm{~B}$ & D 7 B & \\
\hline L23 & 1vo-plec & vil9o, & B38c & \begin{tabular}{|l|l|l|} 
B & $B 4$ & $B$ \\
\end{tabular} & 4 \\
\hline 224 & Sveater sk1rt & ANQO, VUL10/ & $446 \mathrm{~B}$ & C 6 C 6 & \\
\hline L 26 & 5 Cout & $\mathrm{BE} 65, \mathrm{C1}$ & 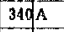 & $\begin{array}{lll}C 5 & B \text { B } \\
\end{array}$ & \\
\hline $\mathrm{L} 26$ & 5 Coat & $8 \pi 100$ & $749 \AA$ & $\begin{array}{lll}C 5 & B \\
\end{array}$ & 3 \\
\hline 227 & 1nono dress & $51 \mathrm{~S} \times 100$ & $727 \Lambda$ & B 4 B E B & \\
\hline$M 1$ & i pajama the & Cr1100 & $316 \mathrm{D}$ & $\mathrm{CE} C \mathrm{CB}$ & \\
\hline$M 2$ & Pajaza & $\mathrm{E} 770, \mathrm{PE} 30$ & $473 \mathrm{~B}$ & D $7 \mathrm{~B} 7 \mathrm{C}$ & \\
\hline$M \quad 3$ & Pajang & $E \div 70,1$ & $453 \mathrm{C}$ & $\begin{array}{lll}D & A 8 \\
\end{array}$ & \\
\hline$M \quad 4$ & Iraining vear & Et100/ & $789 \mathrm{~B}$ & D B & \\
\hline$M \quad 5$ & P-shirt \& trousers & $\mathrm{FE} 65, \mathrm{CT} 35 /$ & $700 \mathrm{~A}$ & $\mathrm{C} 5 \mathrm{D} 6 \mathrm{C}$ & \\
\hline$M 6$ & Bath robo & Crivo & 3300 & D 7 C 7 D & \\
\hline$M 7$ & Yukata dress & $0 \pi 100$ & 3090 & C E D 60 & \\
\hline$M$ s & Yukata dress & EEG5, CT35 & 4800 & 07070 & \\
\hline$M 9$ & fuaper trousers & NL100/PE35, & $600 \mathrm{~A}$ & D 7 B $7 B$ & 3 \\
\hline$M 10$ & Sults & 4100 & 1200 & B 3 $\triangle 7$ & 3 \\
\hline M11 & UtGper \& trousers & AR90, PB10/PE65RY3 39 & 393 & 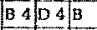 & 2 \\
\hline$M 12$ & Sults & FE5, UL45 & $737 \mathrm{~A}$ & B 4/A.4 A & 3 \\
\hline$M \pm 3$ & Borking o & PeEs, c13 & $626 \mathrm{~A}$ & C6/A7/B & \\
\hline$M 14$ & f twono $d x$ & mit & $1400 \mathrm{~A}$ & 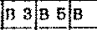 & Dri \\
\hline$M 15$ & sult & C7100 & $1400 \mathrm{~B}$ & C8 & \\
\hline$M 16$ & Jusper \& trouse & NL100/mL100 & $926 \mathrm{~A}$ & \begin{tabular}{ll|l|l|l|l|l|} 
& $B 2$ & $A$
\end{tabular} & 3 \\
\hline$M 17$ & Coat & EEGO, YLAO & $740 \Lambda$ & $\begin{array}{lll}\mathrm{C} 5 \mathrm{~B} & \mathrm{~B} \\
\mathrm{~B}\end{array}$ & \\
\hline$M 18$ & Yorking cloth & $1880, * 1120$ & 390 & $\Lambda 0 \hat{A O}$ & \\
\hline
\end{tabular}

Note:

*1 B:Boy, G:Girl, L:Lady and M:Man

*2 CT:Cotton, WL:Wool, PE:Polyester, AN:Polyacrylonitrile, NL:Nylon $\mathrm{PU}:$ Polyuretane, RY:Rayon, AA:Aromatic polyamide

*3 Numerical value indicates the number of thermoplates counted. 


\section{CONCLUSION}

The fire tests using thermal mannequins dressed in 73 sets of everyday garments showed that all of them, except for 18 sets, exhibited fierce combustion for 10-second contact with a gas flame and also indicated a possibility of causing serious fire injuries to the body within a short time. on the other hand, some clothes were proved to be fire proofed and these were classified into three groups: one group is that the material itself is fire resistant, such as aromatic polyamide, wool and silk; another is that the fiber melts and falls in drops, such as polyester and nylon; and the third group is that the material is thick or fits the body like jeans, though the material itself is flammable, such as cotton. Standards of classification, such as burning rate, size and degree of fire injuries and a combination of these factors were proposed to be viable.

\section{ACKNOWLEDGEMENT}

We are deeply grateful to Mr. Hideo Terasaki, Chief of the Research Division of the Japan Fire Retardant Association for a great amount of information for this study. We also extend our thanks to Mr. Akira Kubota, a student of this department, for his assistance in our tests, Messrs. Kazuhiko Tamura and Hiroshi Morijiri, research students, Mr. Gouichiro Kuwaki and Miss Kaoru Shimogawara, students of this department, for helping with data processing.

\section{REFERENCES}

1. Fire Defence Agency of Japan, Annual White Paper on Fire Service

2. Data from the Tokyo Fire Department Agency (1980)

3. Finley, E.L.: "I gnition System used as a Testing Technique for studying Garment Flammability," J. Fire and Flammability, 1: 166-174 (1970)

4. Finley, E. L. and Carter, W. H.: "Temperature and Heat-Flux Mea surements on Iife-Size Garments ignited by Flame contact," ibid., 2: 298-320 (1971)

5. Finley, E. L. and Butts, C. T.: "Garment Conformation on a Mannequin changes Flammab le Characteristics," ibid., 4: 145-155 (1973)

6. Chouinard, M. P., Knodel, D. C. and Arnold, H. W.: "Heat Transfer from Flammable Fabrics," Textile Research Journal, 431: March 1973

7. Seaman, R. E.: Bull. N.Y. Acad. Med., 43: 8, 649 (1967)

8. Henriques, F. C., Ir.: Archives of Pathology, 43: 489-502 (1947)

9. StolI, A. M. and Greene, L. C.: J. Applied Physiology, 14: 373-382 (1959)

10. Stoll, A. M. and Chianta, M. A.: "Burn Production and prevention in Convective and Radiant Heat Transfer," Aerospace Med., 39: 1097-1100 (1968)

11. Moritz, A. R. and Henriques, F. C.,Jr.: American Journal of Pathology, 23: 695 (1947)

12. Ministry of International Trade and Industry: "On the Results of Tests of Flammability of Children's Yukata Dresses" (1980)

13. Ohya, H.: Garment Flammability and Heat Injury, 60, Maruzen, Tokyo (1983)

14. Braun, E., Cobble, V. B., Helzer, S., Krasny, J. F., Peacock, R. D. and Stratton, A. K.: "Back-Up Report for the Proposed Standard for the Flammability of General Wearing Appare1," NBSIR 76-1072, National Bureau of Standards, Washington, D. C. (1975)

15. Cooperative Industry Program on General Apparel Flammability (1977) 